ISSN: 2542-2812

Journal of Business and Social Sciences Research (JBSSR) Editorial

\title{
Readying Organisations for the third Decade of the Millennium
}

\begin{abstract}
A s we move towards the third decade of the New Millennium, organisations face a heightened need to ready themselves for the new challenges that could unfold in the face of rapidly changing external environments. With the onslaught of artificial intelligence, digitisation, internet of things (IoT), and ICT advances that are there to remain strong, organisations are faced with the imperative need to make these technological wonders complementary and supplementary to human intelligence, so that they would not displace the humans. The indispensability of human resources and talents can never be contested; they should be accorded due priority and respect.

The world of our times also has to deal occasionally with extremist elements resulting from ultra-nationalism and religious intolerance that could adversely affect the politico-economic environment posing challenges to organisations. Additionally, rapidly changing market dynamics is always there to affect them. Another challenge is likely to stem from the present pace of globalisation, as the recent outbreak of an 'unknown' killer disease- subsequently identified as novel corona virus disease in the Chinese city of Wuhan late December this year - has hit human populations. China is a country that accounts for one of the biggest chunks of the global trade, and a substantial share in international investment, and is among the top three most visited countries in the world; overall, China is so inextricably connected with the rest of the world. Since the globalisation waves - that have undoubtedly offered so many advantages to the humankind and eased international travels and trade, inter alia - are also likely to spur the spread of corona virus to the populations across the globe unless the killer disease is nipped in the bud. There is the need to work collaboratively in building resilience from such crises.
\end{abstract}

Therefore, management think-tanks, academicians as well as managers certainly are likely to face newer challenges and opportunities, as a spell of uncertainty and unpredictability reigns in. We, at JBSSR, have also been working to contribute our mite to the world of management and social sciences research in exploring newer frontiers that help better organisations and human lives by making them sustainable in the long term.

Meanwhile, in the short term, the recent change in the journal layout and editorial contents followed by the change at the helm of editorial affairs of the JBSSR has received overwhelming response and laurels that have inspired our editorial team to exert more meaningful efforts in augmenting the quality of its publication. One of the testimonies to it is the initiative to obtain the DOI (digital object identifier) from CrossRef that contributes to the global recognition of every paper published in the JBSSR. We extend our sincere thanks to all the stakeholders and express our willingness to celebrate with them the achievement however small it may be. We look forward to constructive feedback from our valued readers and academic research fraternity.

- Prof. Arhan Sthapit, $P h D$ Chief Editor 


\section{Journal of Business and Social Sciences Research (JBSSR)}

(The double blind, peer-reviewed journal of Ace Institute of Management)

\section{DOUBLE-BLIND, PEER REVIEW STATEMENT}

The JBSSR is a journal that operates a double blind, peer review process: every paper is reviewed by subject and domain experts by ensuring anonymity of both authors and reviewers. The chief editor sends the paper for blind, peer review after performing initial screening. Then, the authors are apprised of the comments received from the refereed reviewers so that the former incorporate the latter's comments into their papers.

So improved papers are submitted to the editorial team following which the Chief Editor reverts them to the reviewers if the improved submission does not still meet the scientific quality meant for a research journal. The final, improved paper is finally edited and formatted by the Chief Editor for publication.

\section{Acknowledgement to reviewers}

The JBSSR editorial team recognises the value and importance of peer reviewers in the overall publication process - not only in shaping individual manuscripts, but also in shaping the credibility and reputation of our journal.

We are committed to the timely publication of all original, innovative contributions submitted for publication. As such, the selection of reviewers who have expertise and interest in the topics appropriate to each manuscript is essential elements in ensuring a timely, productive peer review process.

We would like to take this opportunity to thank the blind, peer reviewers who participated in shaping this volume of JBSSR. We appreciate the time taken to perform the review successfully.

\section{Special thanks to:}

- Prof. Subarna Lal Bajracharya, PhD (Tribhuvan University)

- Asct. Prof. Jeetendra Dangol, PhD (Public Youth Campus, Tribhuvan University)

- Asst Prof. Gangaram Bishwakarma, PhD (School of Management, Tribhuvan University)

- Sunil Chitrakar, PhD (Mahaguthi)

- Asst Prof. Sanjay Ghimire, MPhil (Public Administration Campus, Tribhuvan University)

- Asst Prof. Bikash Shrestha, MPhil (Public Youth Campus, Tribhuvan University)

- Ms. Puja Tamang, Research Officer, Ace Research Centre 